
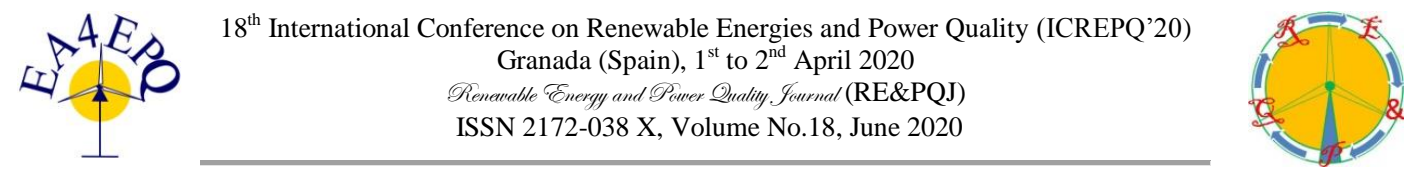

\title{
A Six Legs Buck-boost Interleaved Converter for KERS Application
}

\author{
Gianpaolo Vitale ${ }^{1}$, Emiliano Pipitone ${ }^{2}$ \\ ${ }^{1}$ ICAR, Institute for high performance computing and networking, National Research Council of Italy, \\ via Ugo La Malfa 153, Palermo, Italy. Email: gianpaolo.vitale@icar.cnr.it; \\ ${ }^{2}$ Department of Engineering, University of Palermo, Viale delle Scienze, Palermo, Italy; emiliano.pipitone @ unipa.it
}

\begin{abstract}
This paper addresses the design of a bi-directional DC/DC power converter to interface a supercapacitor bank and a motor-generator unit. The design is based on an interleaved six legs topology in which the current is shared among six inductors to minimize their weight and cost, allowing, besides, a low switching frequency to lessen switching losses. The converter is conceived to be employed in an electric Kinetic Energy Recovery System for Internal Combustion Engine Vehicles. The system makes use of a supercapacitor as a storage system, and a motorgenerator unit connected to the drive shaft for vehicle acceleration and braking. The system uses available commercial devices, thus obtaining a cheap and high-efficiency conversion chain. It is shown how the design criteria differ from traditional interleaved converters. The same topology allows minimizing the input and output ripple and improving the reliability in case of fault as well. Losses are reduced both by sharing the currents and by a suitable control strategy, which allows more converters to be connected in parallel to increase the delivered power. Results, given in simulation, assess the stability and dynamic performance of the conversion circuit, showing a low current and voltage

ripple in all operating conditions.
\end{abstract}

Key words. Hybrid Vehicle; Urban Driving Cycle;

Kinetic Energy Recovery System; KERS; Supercapacitor; Vehicle Fuel economy; Regenerative Braking.

\begin{tabular}{ll} 
& \multicolumn{1}{c}{ Nomenclature } \\
CCM & Continuous Conduction Mode \\
DLC & Double Layer Capacitor \\
ESRDC & Parasitic resistance of the supercapacitor \\
EUDC & Extra-Urban Cycle \\
EV & Electric Vehicle \\
HEV & Hybrid Electric Vehicles \\
ICEV & Internal Combustion Engine Vehicle \\
KERS & Kinetic Energy Recovery Systems \\
MGU & Motor Generating Unit \\
NEDC & New European Driving Cycle \\
PC & Power Converter \\
RBS & Regenerative Braking Systems \\
RGSE & Revised Generalized Steinmetz Equation \\
$S C$ & supercapacitor \\
$C$ & Output capacitor of the six-legs DC/DC converter \\
$D$ & Duty cycle of the power switch of the six-legs \\
$\Delta I_{L}$ & DC/DC converter \\
$\Delta I$ & Peal-to-Peak current variation in an inductor of the \\
$\Delta V o$ & six-legs DC/DC converter \\
$E_{a c c}$ & Peal-to-Peak input current of the six-legs DC/DC \\
$E_{b r a k}$ & converter \\
$f s$ & Peal-to-Peak of the AC component of the output \\
& voltage of the six-legs DC/DC converter \\
& Energy required during acceleration phase \\
& Energy required during braking phase \\
& Switching frequency of a power switch of the six- \\
& legs DC/DC converter
\end{tabular}

\begin{tabular}{|c|c|}
\hline$G(s)$ & $\begin{array}{l}\text { Closed loop transfer function of the six-legs DC/DC } \\
\text { converter }\end{array}$ \\
\hline$G_{v}(s)$ & $\begin{array}{l}\text { Transfer function in Laplace domain of the output } \\
\text { voltage versus the duty cycle of the six-legs DC/DC } \\
\text { converter }\end{array}$ \\
\hline$G_{i L}(s)$ & $\begin{array}{l}\text { Transfer function in Laplace domain of the current } \\
\text { through an inductor versus the duty cycle of the six- } \\
\text { legs DC/DC converter }\end{array}$ \\
\hline $\bar{I}$ & Mean value of the current \\
\hline ID & $\begin{array}{l}\text { Current flowing through a diode of the six-legs } \\
\text { DC/DC converter }\end{array}$ \\
\hline$I_{D S}$ & $\begin{array}{l}\text { Rated current of a power switch of the six-legs } \\
\text { DC/DC converter }\end{array}$ \\
\hline$I_{L}$ & $\begin{array}{l}\text { Current flowing through an inductor of the six-legs } \\
\text { DC/DC converter }\end{array}$ \\
\hline$I_{r r}$ & $\begin{array}{l}\text { Reverse Recovery current of a diode of the six-legs } \\
\text { DC/DC converter }\end{array}$ \\
\hline KI & cancellation factor \\
\hline$L_{C C M}$ & $\begin{array}{l}\text { Minimum value of the inductor to guarantee the } \\
\text { CCM of the six-legs DC/DC converter }\end{array}$ \\
\hline $\mathrm{L}$ & Inductor of the six-legs DC/DC converter \\
\hline $\mathrm{N}$ & Number of legs of the six-legs DC/DC converter \\
\hline$P_{\text {conv }}$ & Rated power of the six-legs DC/DC converter \\
\hline$P c$ & $\begin{array}{l}\text { Power losses for a power switch of the six-legs } \\
\text { DC/DC converter during conduction }\end{array}$ \\
\hline$P c_{-} c$ & $\begin{array}{l}\text { Power losses on the output capacitor of the six-legs } \\
\text { DC/DC converter }\end{array}$ \\
\hline$P_{D_{-} \text {cond }}$ & $\begin{array}{l}\text { Power losses for a diode of the six-legs DC/DC } \\
\text { converter during conduction }\end{array}$ \\
\hline$P_{D_{-} r}$ & $\begin{array}{l}\text { Power losses for a diode of the six-legs DC/DC } \\
\text { converter due to reverse recovery }\end{array}$ \\
\hline$P I_{i}(s)$ & $\begin{array}{l}\text { Proportional Integral regulator of the current of the } \\
\text { six-legs DC/DC converter }\end{array}$ \\
\hline$P I_{v}(s)$ & $\begin{array}{l}\text { Proportional Integral regulator of the voltage of the } \\
\text { six-legs DC/DC converter }\end{array}$ \\
\hline$R_{d s(O N)}$ & $\begin{array}{l}\text { Conduction resistance of a power switch of the six- } \\
\text { legs DC/DC converter }\end{array}$ \\
\hline$R_{D}$ & $\begin{array}{l}\text { Conduction resistance of a diode of the six-legs } \\
\text { DC/DC converter }\end{array}$ \\
\hline$P_{S W}$ & $\begin{array}{l}\text { Power losses for a power switch of the six-legs } \\
\text { DC/DC converter during switching }\end{array}$ \\
\hline Resr & $\begin{array}{l}\text { Parasitic resistance of the output capacitor of the six- } \\
\text { legs DC/DC converter }\end{array}$ \\
\hline$R_{L}$ & $\begin{array}{l}\text { Parasitic resistance of an inductor of the six-legs } \\
\text { DC/DC converter }\end{array}$ \\
\hline$t_{\text {on }}$ & $\begin{array}{l}\text { Turn-on time of a power switch of the six-legs } \\
\text { DC/DC converter }\end{array}$ \\
\hline$t_{\text {off }}$ & $\begin{array}{l}\text { Turn-off time of a power switch of the six-legs } \\
\text { DC/DC converter }\end{array}$ \\
\hline$t_{r r}$ & $\begin{array}{l}\text { Reverse recovery time for a diode of the six-legs } \\
\text { DC/DC converter }\end{array}$ \\
\hline Vo & $\begin{array}{l}\text { Output voltage diode of the six-legs DC/DC } \\
\text { converter }\end{array}$ \\
\hline$V_{\text {DSS }}$ & $\begin{array}{l}\text { Maximum drain-source rated voltage of a power } \\
\text { switch of the six-legs DC/DC converter }\end{array}$ \\
\hline$V_{S C}$ & Voltage across the terminal of the supercapacitor \\
\hline$V \gamma$ & $\begin{array}{l}\text { Threshold voltage of a diode of the six-legs DC/DC } \\
\text { converter. }\end{array}$ \\
\hline
\end{tabular}

$G(s)$ 


\section{Introduction}

The development of Sustainable mobility requires the exploitation of new solutions to reduce fuel consumption and to respect the environment. Among these, growing attention is addressed to road transport emission and urban pollution [1-2], advances in combustion optimization [3], and control [4] of alternative and cost-effective fuels, as well as the optimal management of vehicles drive-line [56]. Nevertheless, one of the heaviest lack of traditional internal combustion engine vehicles (ICEV) is the massive amount of energy lost by friction during the braking phases. This energy, suitably recovered, could be efficiently employed during acceleration, contributing to lower the energy consumption of the vehicles and the related pollution.

To face up with these issues, several Regenerative Braking Systems (RBS) or Kinetic Energy Recovery Systems (KERS) have been studied and optimized for different kinds of vehicles (Electric, Hybrid, or Internal combustion engine vehicle). They can be equipped with an energy storage system of different type (mechanical, electrical, chemical, hydraulic), and suitable or not for retrofit application on current production vehicles. In Hybrid Electric Vehicles (HEV), as well as in pure Electric Vehicles (EV), the presence of power generator and/or motor interfaced to high capacity energy storage allows an easy implementation of regenerative braking, using fuel cells, battery, or supercapacitors (SC) as storage systems.

Recently, the so-called starter-generator systems have been considered for vehicle powering in starting and generating functions. Their growth, both in rated power and control complexity, could improve the hybridization on all vehicles thanks to the reduction of the cost of power electronics and other related technologies [7]. Lately, the development of advanced storage systems as supercapacitors has strengthened to manage the energy exchange in extreme braking conditions [8, 9, 10]. Usually, SCs are used together with traditional battery $[11,12]$, where they are strategic to manage the energy storage by buffering the battery during power transients and enabling more significant acceleration and regenerative braking capabilities [13]. The voltage adaptation between the starter/generator and/or the battery is performed by suitable power converters to guarantee a bidirectional flow of energy and high conversion efficiency $[14,15]$. Differently from the papers mentioned above, the proposed approach considers only SCs as a storage system to exchange energy with the startergenerator. It aims to obtain a cheaper plug-in system for large scale internal combustion engine vehicles in urban transportation.

The use of supercapacitors as a fast and efficient energy storage solution in power applications is widely recognized. In fact, they offer higher power densities to traditional batteries and energy densities from 10 to 20 times higher than electrolytic capacitors. The so-called Double-Layer-Capacitors (DLCs) are available on the market with capacitance values up to $1500 \mathrm{~F}$; even if the voltage of a single unit is low (about $2.7 \mathrm{~V}$ ) higher rated voltages can be obtained by suitable series-parallel arrangements [16]. One of the major drawbacks of this technology consists of its low volumetric and gravimetric energy density in comparison with batteries or fuel cells.
However, DLCs become an interesting option when highly dynamic charging or discharging profiles are concerned, with high current rates [16]. This is justified by their relevant high power capabilities (specific power densities up to about $3400 \mathrm{~W} / \mathrm{kg}$ and specific energy up to $30 \mathrm{Wh} / \mathrm{kg}$, and life cycles of up to $10^{6}$ ) [17].

Unlike electrified vehicles, Internal Combustion Engine Vehicles (ICEV) are not equipped with a generator, motor, and batteries of adequate power and capacity to perform regenerative braking. These kinds of vehicles, hence, mechanical, hydraulic, or pneumatic energy storage devices [18] have been proposed to recover the vehicle kinetic energy during braking phases. The comparison among regenerative braking systems, proposed in [19], underlined that the electric energy recovery systems suffer both of losses of energy due to energy transformations and long recharging times. On the other hand, Hydraulic/Pneumatic based solutions exhibit a limited energy storage, and for flywheels based systems, a loss of rotational energy over time due to friction and air resistance is noticeable. The proposed approach aims to improve the efficiency of the power conversion chain in electric KERS by a suitable design of the DC/DC converter and to adopt supercapacitors as storage units. In particular, the system presented in this paper is intended for the application to ICEV. It is composed of a SC interfaced to a motor-generator unit (MGU) through a power converter, whose function is to adapt the voltage levels between SC and MGU during operation. A feasibility study of the system has been already proposed in [20], the theoretical analysis in [21], and a simulation of the whole system in [22]. This paper analyses the design of a Buck-boost power converter to manage the electric power energy exchange between the SC and the MGU. It is shown that the efficiency of the DC/DC converter plays a key role since the power is processed twice. Its main features are the modularity and efficiency achieved, minimizing the cost of the hardware.

\section{The KERS Operating Principle}

The Kinetic Energy Recovery System (KERS) considered in this work is composed of a supercapacitor, as the energy storage of the system. It is electrically interfaced, through the power converter (PC) developed in this paper, to the motor-generator unit (MGU). It is mechanically connected to the drive shaft and then to the wheels via a fixed gear ratio. During braking, the MGU converts the kinetic energy of the vehicle into electric energy; the power converter has to operate the necessary conversion of voltage and current to transfer this energy to the SC. On the contrary, during acceleration, the SC delivers energy to the power converter that supplies the MGU, which contributes to vehicle propulsion through the drive shaft. The whole system is bidirectional, thus allowing the mechanical energy to be converted into electrical energy (braking) and vice versa (acceleration). The power converter comprises two stages: a DC/DC and a DC/AC. This paper is focused on the design of the $\mathrm{DC} / \mathrm{DC}$ stage. It is connected to the SC and to the DC/AC inverter of the MGU. The SC voltage is lower than the voltage at the DC/AC stage. For this reason, the DC/DC converter will be operated in boost mode (increasing the voltage of the SC to supply the inverter) during 
acceleration. Instead, during braking, it will be operated in step-down mode (lowering the voltage of the DC/AC to charge the SC).

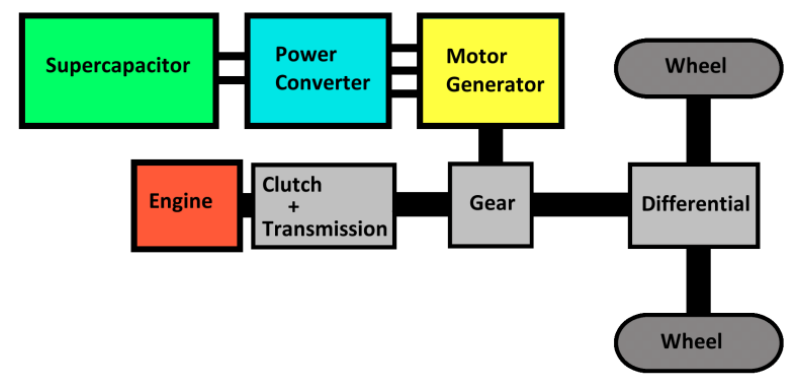

Fig. 1. Schematic representation of the KERS

\section{DC/DC Converter Constraints Design}

The voltage of both the storage system and of the MGU are two constraints for the DC/DC converter together with the rated power. They depend on the vehicle and its performance during braking and acceleration.

\subsection{The Supercapacitor Storage System}

The Supercapacitor based storage system has been chosen based on of the New European Driving Cycle (NEDC), it consists of four repetitions of the urban cycle ECE-15 and one of extra-urban cycle EUDC [23].

The energy delivered from the SC bank to the MGU has been calculated in the worst case for a compact car whose mass is equal to about $980 \mathrm{~kg}$. It corresponds to a peak of $10.3 \mathrm{~kW}$ reached at the end of the acceleration taken during the cycle ECE-15 as shown in figure 2.

$$
E_{a c c}=\int_{t} P d t=32.9 W h
$$

The energy received during braking can be calculated in the same way. From figure 2 the maximum power reaches $6 \mathrm{~kW}$ and the energy to be stored is given by:

$$
E_{\text {brak }}=\int_{t} P d t=3.33 W h
$$

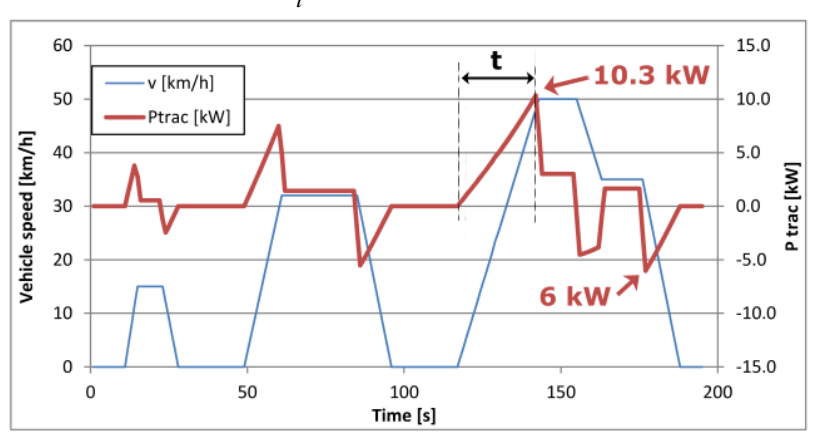

Fig. 2. Speed and power for the urban vehicle under study

On this basis the Maxwell SC Unit BMOD0083 P048 has been chosen. Its main features are:

- Rated Capacitance: $83 \mathrm{~F}$

- Maximum ESRDC, initial: $10 \mathrm{~m} \Omega$

- Rated Voltage: $48 \mathrm{~V}$

- Absolute Maximum Voltage: $51 \mathrm{~V}$

- Absolute Maximum Current: $1150 \mathrm{~A}$
This $S C$ unit can deliver $26.5 \mathrm{Wh}$. This value is slightly lower than that calculated with (1); it comes from a tradeoff: the higher capacity of the supercapacitor bank would improve performance but increasing the weight and cost. $[21,22]$.

\subsection{The Motor Generator Unit}

The MGU has to guarantee the conversion from mechanical to electric energy and vice versa. It has been selected considering the peak of power. The MGU Motenergy ME0201013601 has been chosen. This is a 3phase, Y-connected Permanent Magnet Synchronous Motor with an axial air gap. It exhibits an efficiency equal to $92 \%$ at DC voltage from $12 \mathrm{~V}$ to $96 \mathrm{~V}$ and a continuous current of $60 \mathrm{~A}$. The maximum rotor speed is equal to $5000 \mathrm{rpm}$. The continuous output power is $5 \mathrm{~kW}$ at $96 \mathrm{VDC}$ at $4400 \mathrm{rpm}$ and can deliver a peak output of $13 \mathrm{~kW}$ for 1 minute. This feature is compatible with the duration of the acceleration phase shown in figure 3 . This kind of motor allows the voltage at the output of the DC/DC converter to be fixed to $98 \mathrm{~V}$. This slight increase, compared to the maximum rated voltage, compensates the voltage drop at high currents due to parasitic resistance of electric contacts. It can be noted that as much higher is the operating voltage as lower will be the current for given power so to lessen ohmic losses.

\section{Design of the DC/DC converter}

As far as the topology is concerned, the interleaved structure has been selected since it offers good efficiency and a reduced ripple on the current. Moreover, it assures high reliability since it can be operated with a reduced number of legs in case of failure. In particular, a six legs structure has been studied, as shown in Figure 3.

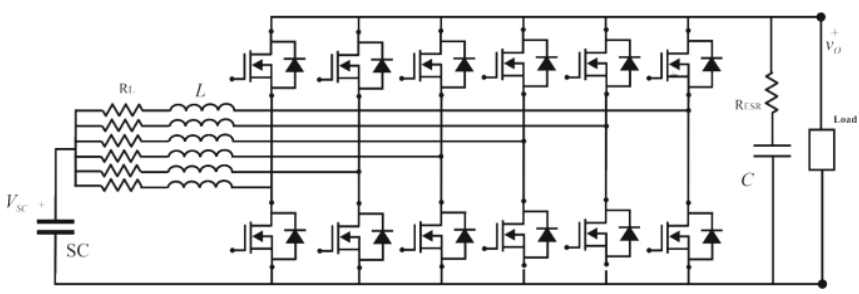

Fig. 3. Electric scheme of the six-legs interleaved converter.

This converter behaves as a Buck or a Boost depending on the devices operated. As an example, the boost mode is obtained for each leg by switching the bottom Mosfet and top with the top Mosfet idle, as shown in figure 4 .

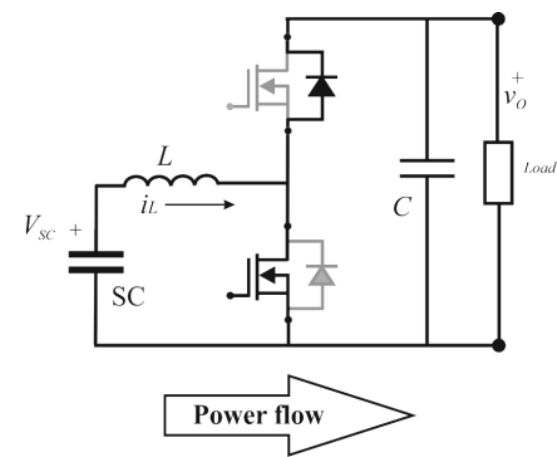

Fig. 4. Electric scheme of one leg of the interleaved DC/DC converter in boost operation. 
The inductor has been designed considering a switching frequency $f_{s}=20 \mathrm{kHz}$ to assure low switching losses in the power devices, and a maximum ripple of the current of $3 \mathrm{~A}$ peak-to-peak. Despite the low value of the switching frequency the fundamental harmonic of the output ripple shows a frequency of $120 \mathrm{kHz}$, and the total output ripple is reduced by the operation of six legs, as it will be shown in the following. The design is performed to maintain the converter operating in Continuous Conduction Mode (CCM) so that the current flows through the inductor without interruption during the switching period. The threshold value of inductor to assure the CCM is calculated in the worst case; it is given by:

$$
L_{C C M}=\frac{V o(1-D) D}{\Delta I_{L} f_{s}}=408 \mu \mathrm{H}
$$

Where $f_{s}$ is the switching frequency, $V o$ is the output voltage, and $\Delta I_{L}$ is the maximum peak-to-peak variation of the input current. The current flowing through the inductor contains a DC value and a triangular-shaped AC component superimposed. To assure the CCM operation, the DC value must be higher than $\Delta I_{L} / 2$. A $500 \mu \mathrm{H}$ inductor is chosen considering a tolerance up to $20 \%$. It is reasonable to assume a maximum current of $10 \mathrm{~A}$ to maintain the cost as low as possible, hence a DC current of $8.5 \mathrm{~A}$ is admitted; on this basis, the rated power of the sixleg converter corresponds to about $2400 \mathrm{~W}$. Higher power can be obtained employing more converters in parallel, as it will be shown later.

The elements that lead to a reduction of the overall cost of the converter are: a) the use of more inductors with a lower rated current, b) the minimization of the input and output filter allowed by the increased frequency of the input and output ripple, c) the reduction of cooling system due to the improved efficiency especially at light load. On the other hand, the converter requires more power devices and gate driver circuitry and a more sophisticated control algorithm; anyway, this complication does not give a significant increase to the cost, as explained in [24]. From now on, the analysis of a single module with $2400 \mathrm{~W}$ of rated power will be carried out. The design constraints of the converter are summarized in table 1 .

Table 1. Constraints Design of the DC/DC converter.

\begin{tabular}{lcl}
\hline \multicolumn{1}{c}{ Parameter } & Symbol & Value \\
\hline Input voltage & $V_{S C}$ & $48 \mathrm{~V}$ \\
Output voltage & $V_{o}$ & $96 \mathrm{~V}$ \\
Number of legs & $\mathrm{N}$ & 6 \\
Rated power & $P_{\text {conv }}$ & $2400 \mathrm{~W}$ \\
Maximum ripple of the & $\Delta I_{L}$ & $3 \mathrm{~A}$ \\
current in a leg & & \\
Maximum current in a leg & $I_{L}$ & $10 \mathrm{~A}$ \\
Switching frequency & $f_{S}$ & $20 \mathrm{kHz}$ \\
\hline
\end{tabular}

The output capacitor is designed considering $D \approx 1$ as worst case and an output voltage ripple $\Delta V o$ of $3 \%$. It results:

$$
C=\frac{D}{R f_{s}\left(\Delta V_{0} / V_{0}\right)}=416 \mu F
$$

The commercial value of $560 \mathrm{uF}$ is chosen, allowing a ripple of about $2.2 \%$, considering a load resistance of $4 \Omega$ as the worst case. As far as the power switches are concerned, a CoolMOS type with 25 A of rated current has been selected. The list of commercial devices, including parasitic components, is given in table 2 .

Table 2. Commercial components of the six legs

\begin{tabular}{|c|c|c|c|}
\hline Symbol & Rated value & Supplier & Code \\
\hline $\mathrm{L}$ & $\begin{array}{l}\mathrm{I}_{\mathrm{L}}=10 \mathrm{~A}, \mathrm{~L}= \\
500 \mathrm{uH}, \mathrm{R}_{\mathrm{L}}=50 \\
\mathrm{~m} \Omega\end{array}$ & Vishay & IHV15BZ500 \\
\hline $\mathrm{C}$ & $\begin{array}{l}560 \mu \mathrm{F}, \text { Resr }= \\
160 \mathrm{~m} \Omega\end{array}$ & Epcos & $\begin{array}{l}\text { B43511A } \\
\text { 4567M007 }\end{array}$ \\
\hline MOSFET & $\begin{array}{l}\mathrm{V}_{\mathrm{DSS}}=650 \mathrm{~V} \\
\mathrm{R}_{\mathrm{DS}}(\text { on })=110 \\
\mathrm{~m} \Omega\left(25{ }^{\circ} \mathrm{C} ; \mathrm{I}_{\mathrm{DS}}\right. \\
=25 \mathrm{~A}\end{array}$ & $\begin{array}{l}\text { Infineon } \\
\text { Techn. }\end{array}$ & $\begin{array}{l}\text { IPA60R125CP } \\
\text { CoolMOS }\end{array}$ \\
\hline
\end{tabular}
interleaved converter.

\section{Efficiency evaluation}

The efficiency has been calculated by evaluating the losses versus the current in each device. The losses depend in different way on the current, they can be constant, linear quadratic with the current, hence it is expected that the efficiency curve will exhibit a maximum [24]; unfortunately during KERS operation, the power transferred between SC and MGU varies appreciably; for this reason, a proper control strategy has been conceived to maximize the converter efficiency apart from the power involved.

The following losses have been considered: a) switching losses on Mosfet devices, b) conduction losses on Mosfet devices, c) conduction losses on a diode, d) diode recovery losses on a diode, e) Joule losses on the parasitic resistance of the inductor and magnetic losses, f) magnetic losses, g) Joule losses on the parasitic resistance of the output capacitor.

The losses have been firstly evaluated for a unique leg operated in the worst case meaning with rated current and $\mathrm{D}=0.5$. The switching losses for a single Mosfet device at rated current of $\mathrm{I}=10 \mathrm{~A}$ and $\mathrm{V}=98 \mathrm{~V}$ are:

$$
P_{S W}=\frac{1}{2} V I\left(t_{o n}+t_{o f f}\right) f_{s} \cong 0.1 W
$$

Where for the selected Mosfet $t_{\text {on }}=t_{\text {off }}=5 \mathrm{~ns}$. The conduction losses on a Mosfet are:

$$
P_{c}=D\left[R_{d s(O N)}\left(\bar{I}_{L}^{2}+\frac{\Delta I_{L}^{2}}{12}\right)\right]=7.3 W
$$

Where the root mean square of the current has been calculated as the sum of the maximum $\mathrm{DC}$ value equal to $8.5 \mathrm{~A}$ and the $\mathrm{AC}$ components which is a triangular waveform with $\Delta I_{L}=3 \mathrm{~A}$.

The power loss on the diode are calculated considering the conduction and the recovery losses:

$$
\begin{gathered}
P_{D_{-} \text {cond }}=D\left[V_{\gamma} \bar{I}_{D}+R_{D}\left(\bar{I}_{D}^{2}+\frac{\Delta I_{L}^{2}}{12}\right)\right]=0.05 \mathrm{~W} \\
P_{D_{-} r r}=\frac{1}{2} V t_{r r} I_{r r} f_{s}=17.3 \mathrm{~W}
\end{gathered}
$$


Where $t_{r r}=430 \mathrm{~ns}, I_{r r}=42 \mathrm{~A}$ for the considered diode integrated into the Mosfet. The power loss on one inductor can be calculated on the basis of the square of rms value of the current multiplied for the parasitic resistance.

$$
P_{L}=R_{L}\left(\bar{I}_{D}^{2}+\frac{\Delta I_{L}^{2}}{12}\right)=3.65 \mathrm{~W}
$$

The magnetic losses have been calculated by the Revised Generalized Steinmetz Equation (RGSE) following the methods explained in [25] obtaining $0.2 \mathrm{~W}$ for each core.

The power loss on output capacitor in the worst case is given by:

$$
P_{C_{-} C}=R_{E S R}(1-D) I_{r m s}^{2}=R_{E S R}(1-D)\left(\frac{\Delta I_{L}}{2 \sqrt{3}}\right)^{2}=0.06 \mathrm{~W}
$$

Where $\mathrm{I}_{\mathrm{rms}}$ is the root mean square value of the AC current through the capacitor, it is equal to $0.87 \mathrm{~A}$.

Table 3. Power losses and efficiency calculation at rated power.

\begin{tabular}{lc}
\hline Loss & Value [W] \\
\hline Mosfet switching losses (x6) & 0.6 \\
Mosfet conduction losses (x6) & 43.8 \\
Diode conduction losses(x6) & 0.3 \\
Diode reverse recovery losses (x6) & 104 \\
Inductor joule losses (x6) & 21.9 \\
Inductor magnetic losses (x6) & 1.2 \\
Capacitor losses & 0.06 \\
TOTAL LOSSES & 171.86 \\
\hline
\end{tabular}

At the rated power of $2400 \mathrm{~W}$, the theoretical efficiency results equal to $92.8 \%$. The equations (5-8) have been implemented versus the output current; then, the converter efficiency has been analyzed considering the operation of two, three, four, five, and six legs with the output current as a parameter. Each leg is operated so that the modulating carriers are phase-shifted of $2 \pi / \mathrm{N}$, where $\mathrm{N}$ is the number of operated legs. In this way, the ripple in the input and output current will be reduced as well as the current through the output capacitor, thus minimizing the losses on $R_{e s r}$. The frequency of the ripple results higher (equal to $120 \mathrm{kHz}$ when all legs are operated), making easier the harmonic suppression.

The ripple on the input current depends on the duty cycle and on the number of operated legs. The analysis of the reduction of the current ripple in interleaved operation mode can be carried out by calculating the cancellation factor $\mathrm{KI}$ as the ratio between the input ripple $\Delta I$ and the current ripple of each inductor $\Delta I_{L}$ as in (10) for $\mathrm{N}=2,3,4, \ldots$ [26]. This value is shown in figure 5, where it can be noted that, for example, when four legs are operated, the complete cancellation is obtained for $D=0.25$ and $D=0.75$.

$$
K I=\frac{\Delta I}{\Delta I_{L}}=N \frac{\prod_{i=1}^{N-1}\left|\frac{i}{N}-D\right|}{\prod_{i=1}^{N-1}\left(\left|\frac{i}{N}-D\right|+\frac{1}{N}\right)}
$$

It can be noted that a three-leg converter could be sufficient to achieve a good ripple cancellation factor. Literature highlights that reduction is not significant for more than four legs, and the number of circuit components increases excessively; on the contrary, for the KERS purposes is appropriate that the number of the legs is augmented to six to adopt cheaper inductors and to improve the efficiency as explained hereinafter.

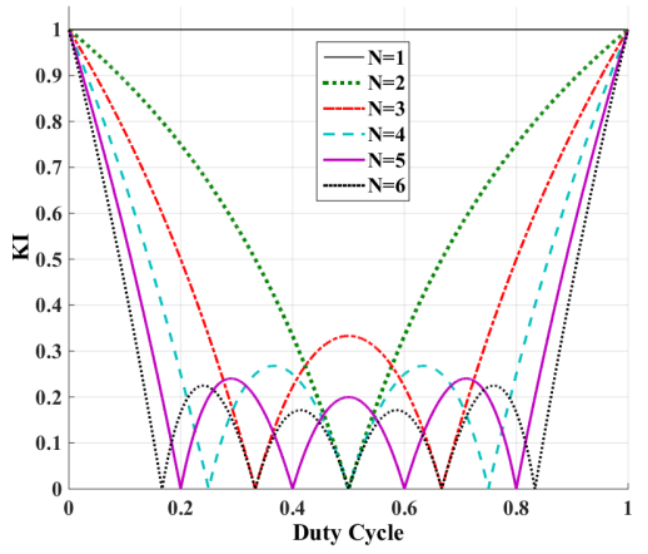

Fig. 5. Cancellation Factor versus duty cycle.

Moreover, this guarantees a redundancy in case of failure of a leg, thus also improving the reliability of the converter. Figure 6 shows the efficiency calculated considering a number of operated legs from one to six versus the input power.

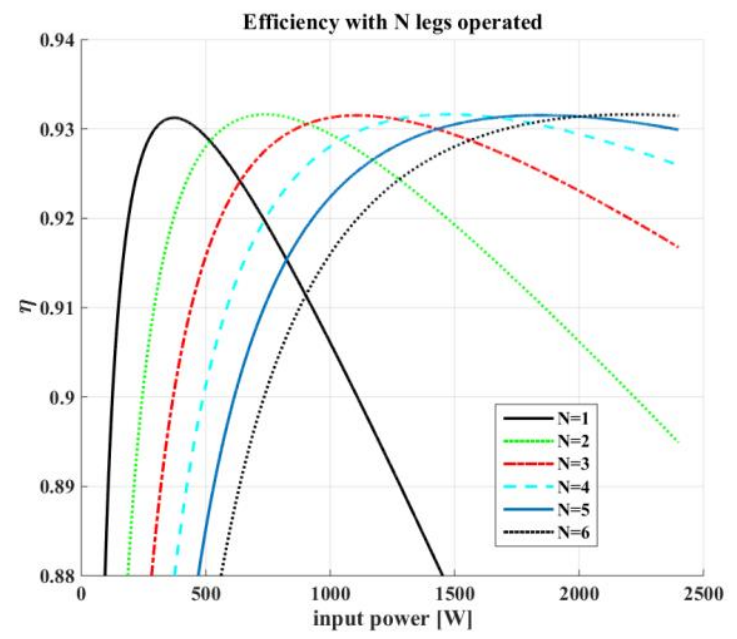

Fig. 6. Comparison of the efficiency for each group of legs operated.

It can be observed that each curve exhibits a maximum in different locations. In order to obtain a high and flat efficiency curve, the control strategy is designed to operate only the first leg up to input power of about $500 \mathrm{~W}$, two legs are operated from $500 \mathrm{~W}$ up to about $900 \mathrm{~W}$ and so on, until the maximum power is reached according to (12).

operated legs : $\left\{\begin{array}{cll}0<P \leq 516 & \text { leg } & 1 \\ 516<P \leq 906 & \text { legs } & 1,2 \\ 906<P \leq 1268 & \text { legs } & 1,2,3 \\ 1268<P \leq 1664 & \text { legs } & 1,2,3,4 \\ 1664<P \leq 2001 & \text { legs } & 1,2,3,4,5 \\ 2001<P \leq 2400 & \text { legs } & 1,2,3,4,5,6\end{array}\right.$


This strategy allowed to obtain the whole efficiency curve represented in figure 7 . It can be noted that the efficiency at rated power calculated by simulating the converter in real operating condition, shown in figure 6 for six legs operated, gives $93.2 \%$ confirming the theoretical worst case analysis shown in table 3 .

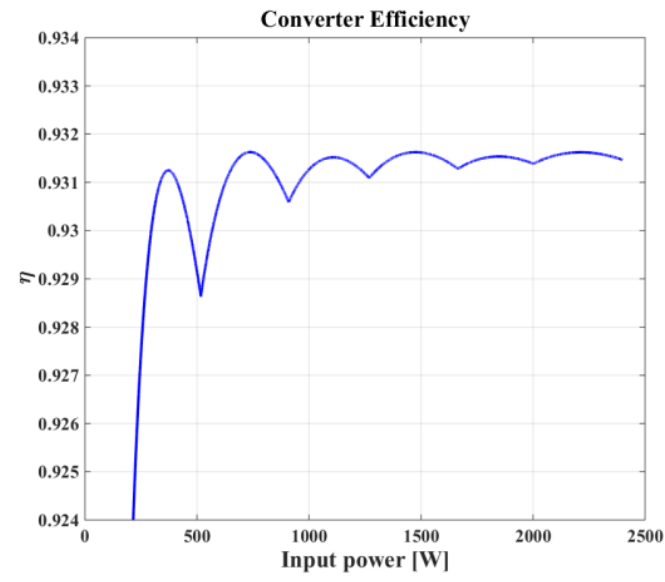

Fig. 7. Total efficiency of the interleaved converter.

\section{Control Strategy}

The control algorithm is based on two loops; a voltage loop to maintain the output voltage constant, and a current loop to force the current in each inductor. Based on the voltage error processed by a PI regulator, the reference current is obtained, it is compared with the current given by the converter, then another PI regulator gives the value of the duty cycle. The number of operated legs is defined by the reference current that depends on the power required or delivered by the SC bank. The current control, imposing the reference current in each inductor, avoids the circulation of parasitic currents. In addition, this feature allows more converters to be connected in parallel to increase the output power. The carrier signals are shifted in phase on the basis of the number of legs to be operated; in this way, the input and output ripple will be minimized, resulting in a frequency much higher than the switching frequency of each leg. The block diagram of the control system is sketched in Figure 8. The two transfer functions giving the voltage and the current versus the duty cycle are [27]:

$$
\begin{aligned}
& G_{v}(s)=\frac{\tilde{v}_{o}(s)}{\tilde{d}(s)}=\frac{s \cdot\left(-R_{L} L i_{L}\right)+R V_{D C}(1-D)-R R_{L} i_{L}}{s^{2} \cdot R L C+s \cdot\left(L+R R_{L} C\right)+R_{L}+R(1-D)^{2}} \\
& G_{i L}(s)=\frac{\tilde{i_{L}}(s)}{\tilde{d}(s)}=\frac{s \cdot V_{D C} R C+R(1-D) i_{L}+V_{S C}}{s^{2} \cdot R L C+s \cdot\left(L+R R_{L} C\right)+R_{L}+R(1-D)^{2}}
\end{aligned}
$$

The two PI regulators have been properly designed, choosing

$$
\begin{aligned}
& P I_{i}(s)=101.8 \cdot[(1+0.00012 / s) / s] \\
& P I_{v}(s)=742.8 \cdot[(1+0.0014 / s) / s]
\end{aligned}
$$

The closed loop transfer function obtained by (13-16) shows a dominant negative real part pole $\mathrm{p} 1=-0.028 \mathrm{rad} / \mathrm{s}$ and a couple of complex conjugate poles $p 2,3=-0.2502 \pm j$ 1.3082 giving an overdamped response of the output voltage.

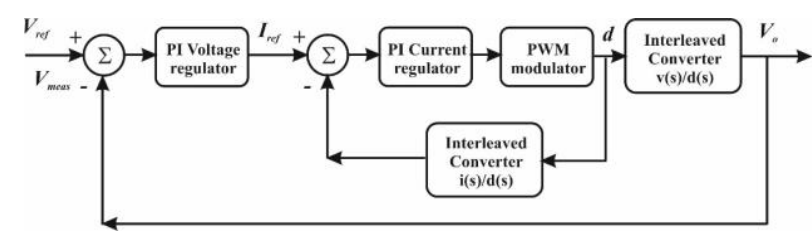

Figure 8. block diagram of the control system

\section{Results}

Simulation results have been carried out to verify the performance of the designed converter, i.e., the reduced ripple of the current, and the dynamic behavior. Figure 9 shows a steady-state test at rated power. Albeit the currents on the six inductors exhibit a period of $50 \mu \mathrm{s}$ (corresponding to the switching frequency of $20 \mathrm{kHz}$ ), the current supplied by the supercapacitor shows a period of $8.33 \mu$ s (corresponding to a fundamental frequency of $120 \mathrm{kHz}$ ) and a ripple of $0.35 \%$. It is much lower compared to the ripple on a single inductor. The load voltage experiences the same period and a ripple of $1.53 \%$. Figure 10 shows a dynamic test obtained by varying the load from $4 \Omega$ to $12 \Omega$ at $\mathrm{t}=0.1 \mathrm{~s}$.
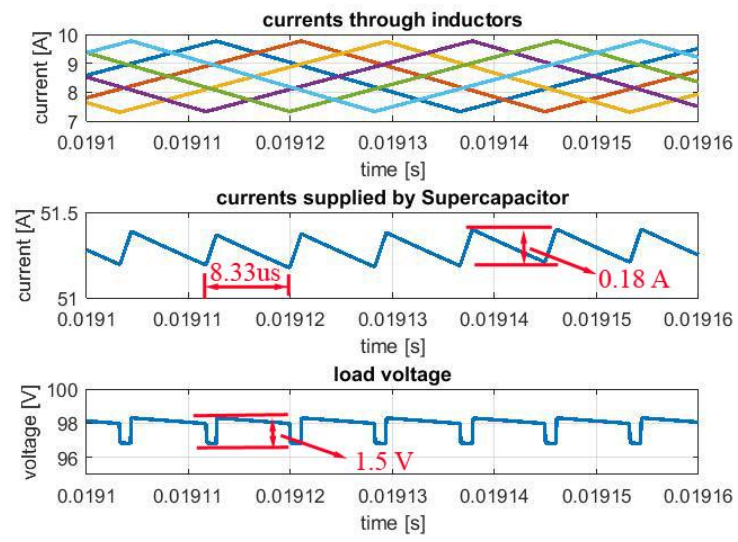

Fig. 9. steady state test at rated power: currents through inductors (top), current supplied by the supercapacitor (middle), load voltage (bottom).
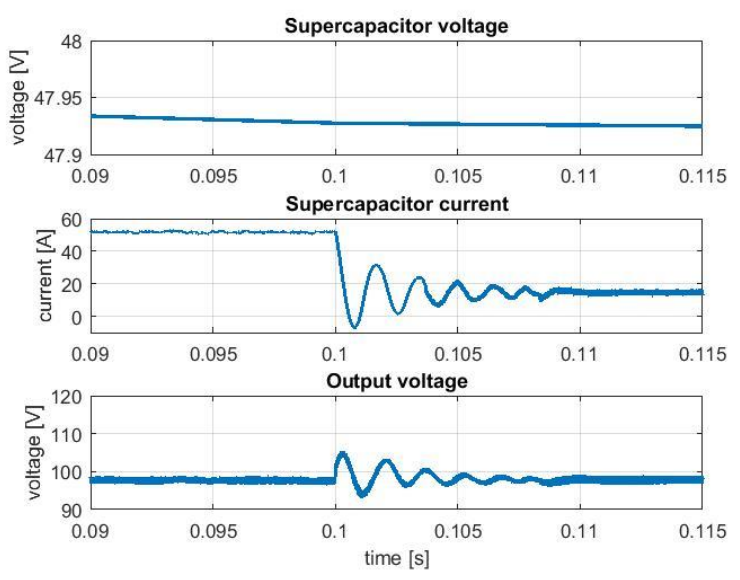

Fig. 10. dynamic test with load variation: supercapacitor voltage (top), current supplied by the supercapacitor (middle), load voltage (bottom). 
It can be noted that, after the load reduction, the slope of the voltage of the supercapacitor is lessened as expected. The current supplied by the supercapacitor after a transient of about $10 \mathrm{~ms}$ reaches the new value, and the voltage on the load is maintained to $98 \mathrm{~V}$ by the control system. A test by varying the reference voltage from $80 \mathrm{~V}$ to $98 \mathrm{~V}$ at $\mathrm{t}=0.03 \mathrm{~s}$ is sketched in figure 11 . The output voltage requires only about $50 \mathrm{~ms}$ to reach the new value, and the overdamped transient confirms the calculation explained in section 6 .

Both the load voltage and the supplied current exhibit a reduced ripple. In particular, the output voltage ripple is equal to $1.5 \mathrm{~V}$ peak-to-peak when the DC output is $98 \mathrm{~V}$, and the ripple of the supplied current is equal to $0.35 \mathrm{~A}$ peak-to-peak when the DC current is 33A. A final test is carried out to reproduce the current required for the $20 \mathrm{~s}$ acceleration phase in which the power rises up to $10.3 \mathrm{~kW}$; it is sketched in figure 3. Firstly, the operating condition of a single power module has been reproduced considering the power rising from zero to $2.4 \mathrm{~kW}$ in $4 \mathrm{~s}$ corresponding to a single DC/DC converter unit. Figure 12 shows the power delivered to the MGU and the output voltage of the DC/DC converter; it can be noted that the voltage ripple remains low even near to the rated power. In figure 13, the current delivered by the SC and the voltage at the terminals of the SC are drawn. Also, in this case, a low current ripple can be appreciated.
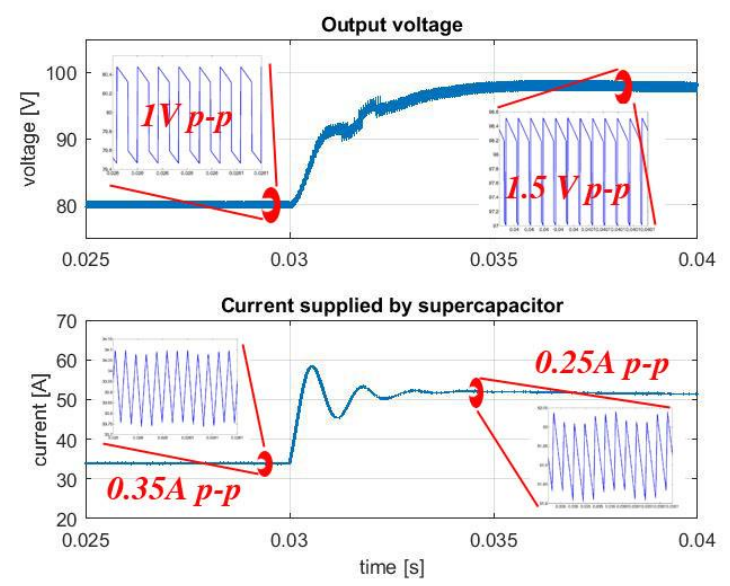

Figure 11. dynamic test with reference output voltage variation: output voltage (top), current supplied by the supercapacitor (bottom).
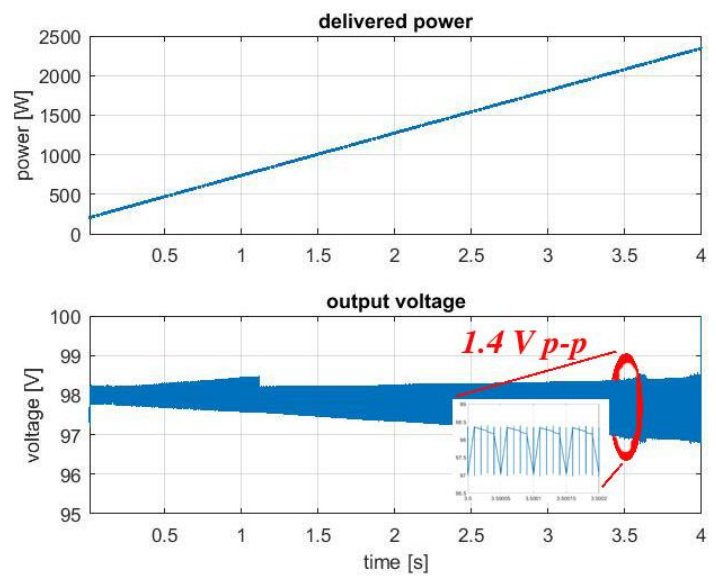

Figure 12. acceleration test: power delivered to the MGU (top), output voltage (bottom).
To satisfy the whole power requirements, five DC/DC power converters parallel connected have to be employed, as shown in figure 14. Each converter is supplied by the supercapacitor bank and delivers power to the DC/AC conversion unit of the MGU drive. Each converter is operated in a range of $4 \mathrm{~s}$ to reach the maximum required power.
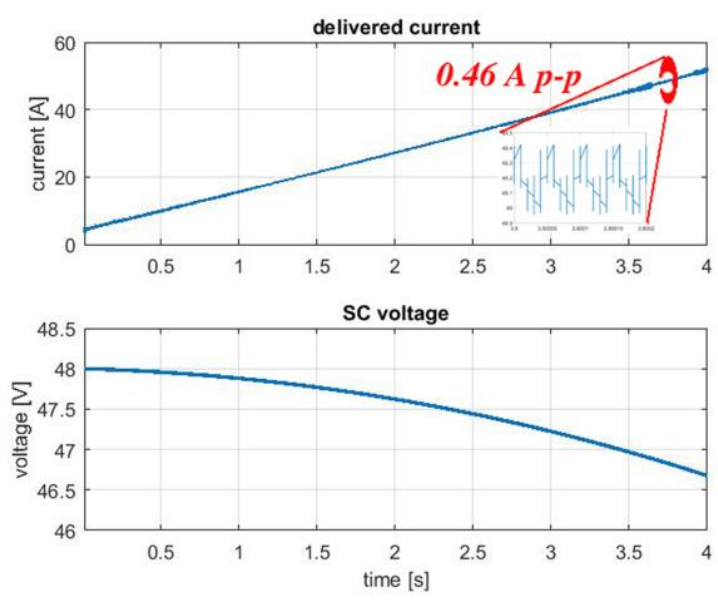

Figure 13. acceleration test: current delivered by the supercapacitor (top), supercapacitor voltage (bottom).

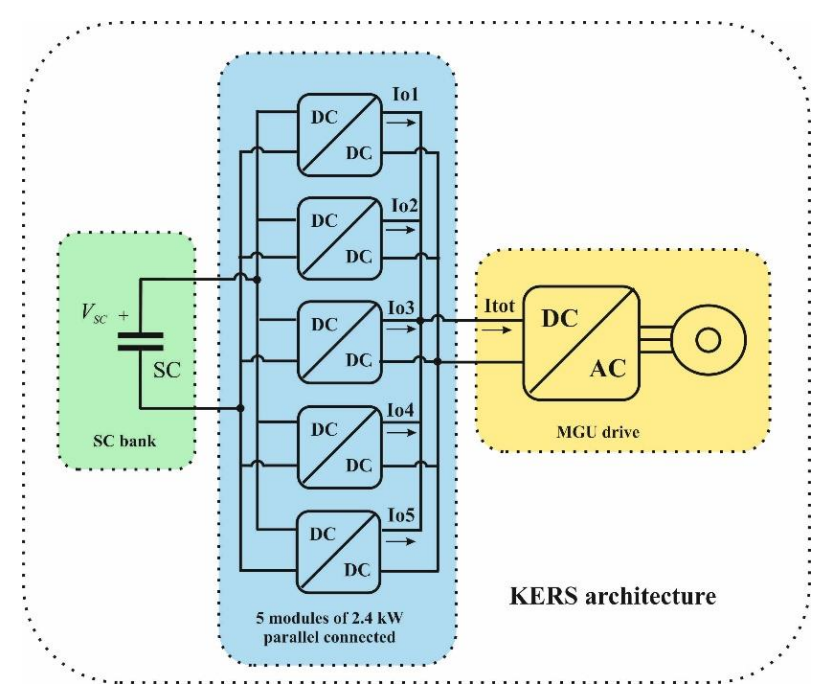

Figure 14. Schematics of the KERS architecture

In order to optimize the efficiency of the system, each converter is started when the previous unit is operated at rated power so that its efficiency is close to the maximum value. In a nutshell, only one converter starts at the beginning until its supplied power reaches the rated value of $2400 \mathrm{~W}$, then it continues to deliver a constant power of $2400 \mathrm{~W}$ and the second converter starts in the same way and so on until the fifth converter supplies the rated power.

The waveforms of the current for each DC/DC converter and the total current delivered to the MGU drive are shown in figure 15 . It can be noted that the control system is able to manage the power requirements so that when a converter reaches its nominal power, another converter starts operating. 


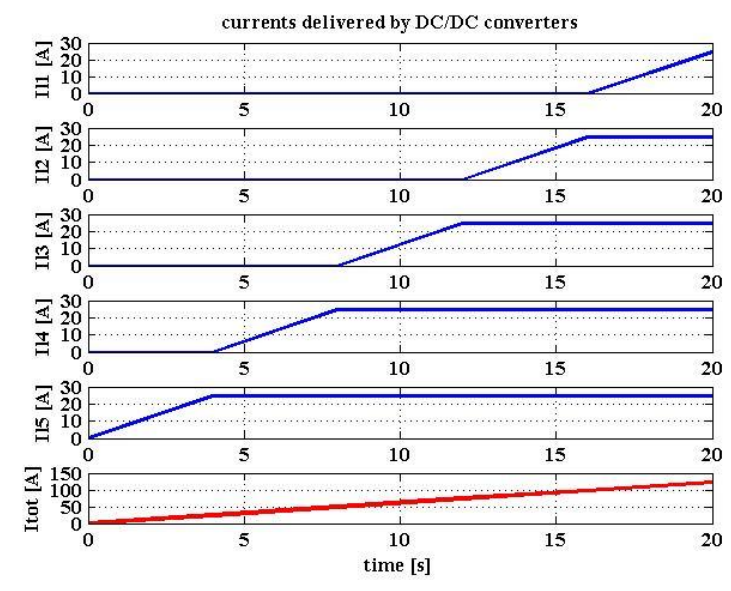

Figure 15. current delivered by DC/DC converters and total current during an acceleration.

\section{Conclusions}

A six legs interleaved converter has been designed to manage the power transfer between a supercapacitor and an motor-generator unit for an electric KERS proposed for internal combustion engine vehicles. The system is conceived to allow a significant saving of fuel, and consequent $\mathrm{CO}_{2}$ reduction, in an urban area. The analysis has been performed based on commercial devices to obtain a cheap realization so that it can be used in low cost vehicles. Differently from a traditional interleaved converter, a greater number of legs has been chosen to guarantee higher efficiency and reliability. The number of legs assures a flat efficiency curve by a suitable choice of the legs simultaneously operated, according to the delivered power. The stability is assured by a control strategy based on voltage and current loops. Steady-state output current and voltage exhibit a very low ripple despite the low switching frequency; indeed, the fundamental harmonic of the output ripple is six times the switching frequency. Finally, the modularity of the proposed solution allows arbitrarily greater power to be managed.

\section{References}

[1] P. Iodice, A. Senatore. "Road transport emission inventory in a regional area by using experimental two-wheelers emission factors." World Congress on Engineering. 2013.

[2] P. Iodice et al. "Air pollution monitoring using emission inventories combined with the moss bag approach." Science of the total environment 541 (2016): 1410-1419.

[3] E. Pipitone, A. Beccari, "A study on the use of combustion phase indicators for MBT spark timing on a bi-fuel engine", No. 2007-24-0051. SAE Technical Paper, 2007.

[4] F. Bue et al. "Misfire detection system based on the measure of crankshaft angular velocity." Advanced Microsystems for automotive applications. Vol. 10. 2007.

[5] M. Cammalleri, F. Sorge, "Approximate closed-form solutions for the shift mechanics of rubber belt variators." ASME 2009 International Design Engineering Technical Conferences and Computers and Information in Engineering Conference. American Society of Mechanical Engineers, 2009.

[6] M. Cammalleri. Efficiency of split-way CVT's. A simplified model. No. 2007-24-0133. SAE Technical Paper, 2007.

[7] B. Lequesne, "Automotive electrification: The nonhybrid story." IEEE Trans. on Transp. Electrif. 1.1, (2015), pp. 40-53.

[8] Z. Zhongyue, et al. "Evaluation strategy of regenerative braking energy for supercapacitor vehicle." ISA transactions 55 (2015): pp. 234-240.
[9] P. Hui, et al. "Controllable regenerative braking process for hybrid battery-ultracapacitor electric drive systems." IET Power Electronics 11.15 (2018): 2507-2514.

[10] I. Khaled, et al. "Regenerative braking modeling, control, and simulation of a hybrid energy storage system for an electric vehicle in extreme conditions." IEEE Trans. on Transp. Electrif. 2.4 (2016): 465-479.

[11] L. Kouchachvili, Y. Wahiba E. Entchev. "Hybrid battery/supercapacitor energy storage system for the electric vehicles." Journal of Power Sources 374 (2018): 237-248.

[12] S. Ziyou, et al. "Energy management strategies comparison for electric vehicles with hybrid energy storage system." Applied Energy 134 (2014): 321-331.

[13] Q. Xu, F. Wang, X. Zhang S. Cui, S. (2019). "Research on the Efficiency Optimization Control of the Regenerative Braking System of Hybrid Electrical Vehicle Based on Electrical Variable Transmission." IEEE Access 7 (2019): 116823-116834.

[14] K. Mahdiyeh, A. A. Mohamed, W. Brandauer. "Recuperation of regenerative braking energy in electric rail transit systems." IEEE Trans. on Intell. Transport. Syst. (2019). [15] A. Furkan, et al. "A bidirectional nonisolated multi-input DC-DC converter for hybrid energy storage systems in electric vehicles." IEEE Trans. on Vehic. Techn. 65.10 (2015): 79447955.

[16] G. Vitale, "Supercapacitor modelling by Lagrange's equations." International conference on modern electrical power engineering, (ICMEPE-2016). 6-8 July, Las Palmas de Gran Canaria, Spain. 2016.

[17] C. Ephrem, et al. "Electrochemical and electrostatic energy storage and management systems for electric drive vehicles: State-of-the-art review and future trends." IEEE Journal of Emerging and Selected Topics in Power Electr. 4.3 (2016): 1117-1134.

[18] Z. Junzhi, et al. "Regenerative braking system for series hybrid electric city bus." World Electric Vehicle Journal 2.4 (2008): 363-369.

[19] W. Matthew et al., "Analysis of a Hybrid Mechanical Regenerative Braking System." MATEC Web of Conferences. Vol. 152. EDP Sciences, 2018.

[20] P. Emiliano, et al. A Feasibility Analysis of an Electric KERS for Internal Combustion Engine Vehicles. No. 2019-240241. SAE Technical Paper, 2019.

[21] E. Pipitone , G. Vitale, "A regenerative braking system for internal combustion engine vehicles using supercapacitors as energy storage elements-Part 1: System analysis and modelling." Journal of Power Sources (2019): 227368.

[22] E. Pipitone , G. Vitale, "A regenerative braking system for internal combustion engine vehicles using supercapacitors as energy storage elements-Part 2: Simulation results." Journal of Power Sources (2019): 227258.

[23] T. Barlow, et al. "A reference book of driving cycles for use in the measurement of road vehicle emissions." TRL Published Project Report (2009).

[24] W. J. Kolar, et al. "Extreme efficiency power electronics." 2012 7th International Conference on Integrated Power Electronics Systems (CIPS). IEEE, 2012.

[25] S. F Roberto, et al. "Equivalent Circuit Modelling of Ferrite Inductors Losses." IEEE 4th Intern.Forum on Research and Technology for Society and Industry (RTSI), 2018.

[26] Durán, E. et al, "An Application of Interleaved Zeta-BuckBoost Combination Converter in Distributed Generation." International Congress on Engineering and Sustainability in the XXI Century. Springer, Cham, 2017.

[27] H. Omar et al, "Analysis, control and comparison of DC/DC boost converter topologies for fuel cell hybrid electric vehicle applications." Proc. of the 14th European Conf. on Power Electronics and Appl. IEEE, 2011. 